\title{
SISTEM PAKAR DIAGNOSA DIABETES MELLITUS DENGAN METODE NAIVE BAYES BERBASIS ONLINE
}

\author{
I Komang Somawirata ${ }^{1}$, Ahmad Fahrudi Setiawan ${ }^{2}$ \\ ${ }^{1)}$ Teknik Elektro, Institut Teknologi Nasional Malang \\ ${ }^{2)}$ Teknik Informatika, Institut Teknologi Nasional Malang \\ komangs@lecturer.itn.ac.id
}

\begin{abstract}
ABSTRAK
Artikel ini merupakan penelitian yang berhubungan dengan diagnose penyakit diabetes, menggunakan system pakar dengan metode naïve bayes yang dilakukan di rumah sakit daerah dr Saiful Anwar kota Malang. Dalam penelitian ini dibuktikan bahwa aplikasi yang rancang dan dibuat telah dapat mengakomodasi pengantian dokter dengan system sebesar $90 \%$ kebenaran. Penelitian yang dilakukan dengan cara mengumpulkan semua gejala dari diabetes tipe A dan tipe B dan dimasukkan kedalam database bernama data training, selanjutnya sesuai dengan keilmuan pakar data tersebut disusun menjadi rule/aturan pengetahuan yang nanti akan digunakan untuk menentukan diagnose penyakit diabetes type A atau type B.
\end{abstract}

Keyword : Diagnosa, diabetes, system pakar, nä̈ve bayes, Rs dr Saiful Anwar kota Malang

\section{PENDAHULUAN}

Saat ini diabetes mellitus merupakan suatu penyakit yang sangat umum di derita masyarakat dunia dan khususnya Indonesia, penyakit ini identik dengan kemakmuran yang menyebabkan perubahan pola makan dan pola hidup yang tidak sehat, banyaknya asupan gula dan kalori yang masuk kedalam tubuh tidak di imbangi dengan aktifitas tubuh yang cukup (olah raga, kerja otot seperti berjalan dan lain sebagainya, banyak orang yang kerja dengan hanya duduk saja), sehingga gula menumpuk dalam darah dan menjadi penyakit kencing manis atau yang lebih umum disebut dengan Diabetes Mellitus. Sistem pakar adalah suatu sistem komputer yang meniru pengetahuan seorang pakar, sistem pakar dapat diterapkan didalam diagnosa penyakit diabetes mellitus sehingga sistem ini dapat secara dini mendeteksi gejala-gejala diabetes mellitus. Akuisisi pengetahuan dari seorang pakar diabetes mellitus dengan menggunakan teorema Naive Bayes dimana data gejala dan diagnosa penyakit yang terdahulu dari seorang pakar dikumpulkan menjadi suatu data training, selanjutnya data gejala dari data testing sebuah dugaan penyakit diabetes dihitung dengan metode Naive Bayes sehingga menghasilkan kesimpulan apakah seseorang tersebut menderita diabetes apa tidak.

\section{METODE PENELITIAN}

\subsection{Analisis Basis Pengetahuan (Knowledge} Base)

Dalam pembangunan sistem berbasis pengetahuan, pengetahuan yang telah diekstrak dipresentasikan ke dalam bentuk yang dapat di proses oleh komputer. Representasi pengetahuan merupakan kombinasi sistem berdasarkan dua elemen, yaitu struktur data dan penafsiran prosedur yang digunakan sebagai pengetahuan untuk menyimpan struktur data.

\subsection{Analisis dengan Teorema Bayes}

Probabilitas bayes merupakan salah satu cara untuk mengatasi ketidak pastian data dengan menggunakan formula bayes yang dinyatakan :

$P(H \mid E)=\frac{P(E \mid H) \cdot P(H)}{P(E)}$

Dimana :

$\mathrm{P}(\mathrm{H} \mid \mathrm{E})=$ Probabilitas hipotesis $\mathrm{H}$ jika diberikan evidence e.

$\mathrm{P}(\mathrm{E} \mid \mathrm{H})=$ Probabilitas munculnya evidence E jika diketahui hipotesis $\mathrm{H}$

$\mathrm{P}(\mathrm{H})=$ Probabilitas hipotesis $\mathrm{H}$ tanpa memandang evidence apapun

$\mathrm{P}(\mathrm{E}) \quad=$ Probabilitas ev

Rumus teorema bayes ini digunakan untuk medapatkan nilai prosentase gejala yang perhitungan probabilitas tiap gejala dengan klasifikasi ya dan tidak. Rumus teorema bayes ini digunakan untuk medapatkan nilai prosentase gejala yang perhitungan probabilitas tiap gejala dengan klasifikasi ya dan tidak . Adapun perhitungan probabilitas diagnosa gangguan diabetes berdasarkan gejala yaitu : 
1. Poliuria

- Probabilitas terkena diabetes jika diabetes (ya);p[diabetes(ya) $\mid$ gejala(ya)].

- Probabilitas terkena diabetes jika poliuria(ya);p[poliuria(ya) $\mid \mathrm{p}(\operatorname{diabetes}(\mathrm{ya})]$.

$\mathrm{p}[\operatorname{diabetes}(\mathrm{ya}) \mid$

$\mathrm{p}[\operatorname{gejala}(\mathrm{n})]$

$$
=\frac{p[\operatorname{diabetes}(\mathrm{ya})] 11}{\mathrm{p}[\operatorname{gejala}(\mathrm{n})] \quad 18}
$$

$\mathrm{p}$ [poliuria( ya) $\mid \mathrm{p}$ [diabetes( ya) 8

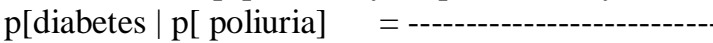
$\mathrm{p}$ [diabetes( ya) $\mid \mathrm{p}$ [gejala] 11

hasilnya $=\mathrm{p}$ [diabetes $] \mid \mathrm{p}$ [gejala $] * \mathrm{p}$ [diabetes $] \mid$ $\mathrm{p}[$ poliuria $]=11 / 18 * 8 / 11=0.4444$

Nilai 11/18 dan 8/11 didapat dari perhitungan klasifikasi gejala yang "ya" dari tiap gejala. Nilai 11 didapat dari perhit ungan hasil "ya" untuk field diabetes dibandingkan dengan banyaknya gejala (18). Sedangkan nilai 8 didapat dari perhitungan "ya" dari field poliuria yang menghasilkan diabetes "ya" dibandingkan dengan $\mathrm{p}[\operatorname{diabetes}(\mathrm{ya})]$ yaitu 11 . Setelah menghitung klasifikasi gejala yang "ya" kem udian dihitung lagi klasifikasi gejala yang "tidak" sebagai bahan pertimbangan antara "hasil ya" dan "hasil tidak" untuk dijadikan keputusan.

Maka klasifikasi penyakit "tidak" adalah : $\mathrm{p}$ [diabetes(t)] $7 \mathrm{p}$ [diabetes $(\mathrm{t}) \mid \mathrm{p}[\operatorname{gejala}(\mathrm{n})]$ $\mathrm{p}[\operatorname{gejala}(\mathrm{n})] 18 \mathrm{p}[\operatorname{poliuria}(\mathrm{ya}) \mid \mathrm{p}[\operatorname{diabetes}(\mathrm{t})] 3$

$\mathrm{p}[$ diabetes $(\mathrm{t}) \mid \mathrm{p}[$ gejala $]] 7$ hasilnya $=\mathrm{p}[$ diabetes $] \mid$ $\mathrm{p}$ [gejala] $* \mathrm{p}$ [diabetes] $\mid \mathrm{p}$ [ poliuria] $7 * 30.166618$ 7

Dari hasil ini kemudian dibandingkan dengan hasil perhitungan sebelumnya yaitu hasil perhitungan dari poliuria ya. Jika hasil "ya" lebih besar maka dapat dikatakan terdeteksi diabetes sedangkan jika hasil "ya" lebih kecil dari hasil "tidak" maka tidak terdeteksi diabetes. Sedan gkan untuk menentukan tipe diabetes apakah diabetes tipe 1 atau tipe 2 maka yang dilihat adalah umur peserta diagnosa, jika umur peserta kecil dari 21 tahun maka peserta tersebut terdeteksi diabetes tipe 1 dan jika umur peserta lebih besar dari 21 tahun maka peserta tersebut menderita diabetes tipe 2 . Begitu juga dengan perhitungan gejala yang lainnya. adapun tabel pengisian gejala dapat dilihat

\begin{tabular}{|c|c|c|c|c|c|c|c|c|c|c|c|c|c|c|c|c|}
\hline No & poliuria & polidipsia & polipagia & kram & kesemutan & rasa_tebal & BB_turun & Kulit & gatal & bisul & infeksi & keputihan & luka & lapar & $\begin{array}{l}\text { gelisah } \\
\end{array}$ & diabetes \\
\hline \begin{tabular}{|l|}
1 \\
\end{tabular} & ya & ya & Ya & tidak & tidak & tidak & ya & tidak & ya & tidak & tidak & tidak & ya & tidak & tidak & ya \\
\hline \begin{tabular}{|l|}
2 \\
\end{tabular} & ya & ya & $\overline{Y a}$ & ya & ya & tidak & tidak & tidak & tidak & tidak & ya & ya & tidak & ya & ya & ya \\
\hline 3 & tidak & ya & Tidak & tidak & tidak & ya & ya & ya & ya & ya & ya & ya & tidak & ya & ya & tidak \\
\hline \begin{tabular}{|l|}
4 \\
\end{tabular} & ya & tidak & Tidak & ya & tidak & ya & tidak & ya & ya & tidak & ya & tidak & tidak & tidak & tidak & tidak \\
\hline 5 & tidak & tidak & Tidak & ya & tidak & ya & ya & ya & $\mathrm{ya}$ & ya & ya & ya & tidak & ya & ya & tidak \\
\hline \begin{tabular}{|l|}
6 \\
\end{tabular} & ya & tidak & Ya & ya & ya & tidak & tidak & tidak & tidak & tidak & tidak & tidak & ya & tidak & ya & ya \\
\hline \begin{tabular}{|l|l}
7 \\
\end{tabular} & ya & ya & Tidak & tidak & ya & tidak & ya & tidak & tidak & tidak & tidak & ya & ya & tidak & tidak & ya \\
\hline 8 & tidak & ya & Ya & ya & tidak & ya & ya & ya & ya & tidak & tidak & ya & ya & tidak & ya & ya \\
\hline \begin{tabular}{|l|}
9 \\
\end{tabular} & tidak & tidak & Ya & tidak & tidak & ya & ya & ya & ya & tidak & tidak & ya & tidak & ya & tidak & tidak \\
\hline 10 & tidak & ya & Tidak & ya & tidak & tidak & tidak & ya & tidak & ya & ya & tidak & tidak & tidak & ya & tidak \\
\hline 11 & ya & ya & $\overline{Y a}$ & tidak & tidak & tidak & tidak & tidak & tidak & tidak & tidak & tidak & ya & ya & tidak & ya \\
\hline 12 & ya & tidak & Tidak & tidak & ya & ya & $\mathrm{ya}$ & $\mathrm{ya}$ & ya & ya & $\mathrm{ya}$ & tidak & tidak & tidak & ya & tidak \\
\hline \begin{tabular}{|l|}
13 \\
\end{tabular} & tidak & ya & $\mathrm{Ya}$ & ya & ya & ya & tidak & tidak & tidak & tidak & tidak & tidak & tidak & tidak & ya & ya \\
\hline 14 & $\mathrm{ya}$ & ya & Tidak & $\begin{array}{l}\text { tidak } \\
\end{array}$ & ya & ya & ya & tidak & tidak & ya & $\mathrm{ya}$ & ya & ya & tidak & tidak & ya \\
\hline 15 & tidak & ya & Ya & ya & ya & tidak & tidak & tidak & ya & ya & ya & ya & ya & tidak & tidak & ya \\
\hline \begin{tabular}{|l|}
16 \\
\end{tabular} & ya & tidak & $\mathrm{Ya}$ & tidak & tidak & tidak & ya & ya & tidak & tidak & tidak & tidak & tidak & tidak & ya & ya \\
\hline \begin{tabular}{|l|}
17 \\
\end{tabular} & ya & ya & $\begin{array}{l}\mathrm{Ya} \\
\end{array}$ & tidak & ya & tidak & tidak & tidak & tidak & tidak & tidak & tidak & ya & tidak & tidak & ya \\
\hline \begin{tabular}{|l|}
18 \\
\end{tabular} & tidak & tidak & Tidak & ya & tidak & ya & ya & ya & ya & ya & ya & ya & tidak & ya & ya & tidak \\
\hline
\end{tabular}
pada tabel di bawah ini :

\section{HASIL DAN PEMBAHASAN}

\subsection{Implementasi}

Teknologi yang digunakan dalam pengembangan sistem ini adalah teknologi aplikasi berbasis web, yang membentuk sebuah program yang dapat berdiri sendiri dan dapat dijalankan dalam lingkungan Internet. Sehingga dimanapun pengguna (user) berada dapat menggunakan aplikasi ini, dengan mengakses situs tersebut secara cepat dan mudah. Dengan sistem web based ini, diharapkan dapat meningkatkan pengetahuan serta memberikan suatu kemudahan dalam hal mendiagnosa diabetes mellitus baik tipe 1 maupun tipe 2.

Dalam proses pengaplikasiannya sistem ini membutuhkan beberapa komponen. Apabila semua komponen pendukung aplikasi sistem pakar untuk mendiagnosa diabetes terpasang (installed) dalam komputer, seperti Macromedia Dreamweaver MX 2004, AppServ 2.5.7, serta browser yang mendukung yaitu Mozilla Firefox, Opera ataupun Internet Explorer. Maka langkah selanjutnya adalah mewujudkan rancangan sistem yang telah dibuat. Berikut ditunjukkan bagian (modul) terpenting dari sistem yang akan di implementasikan.

\subsection{Layout Program}

Pada halaman pilih gejala ini berfungsi untuk memilih gejala-gejala diabetes yang nantinya akan digunakan sebagai proses diagnosa. Adapun desain halamannya adalah sebagai berikut: 


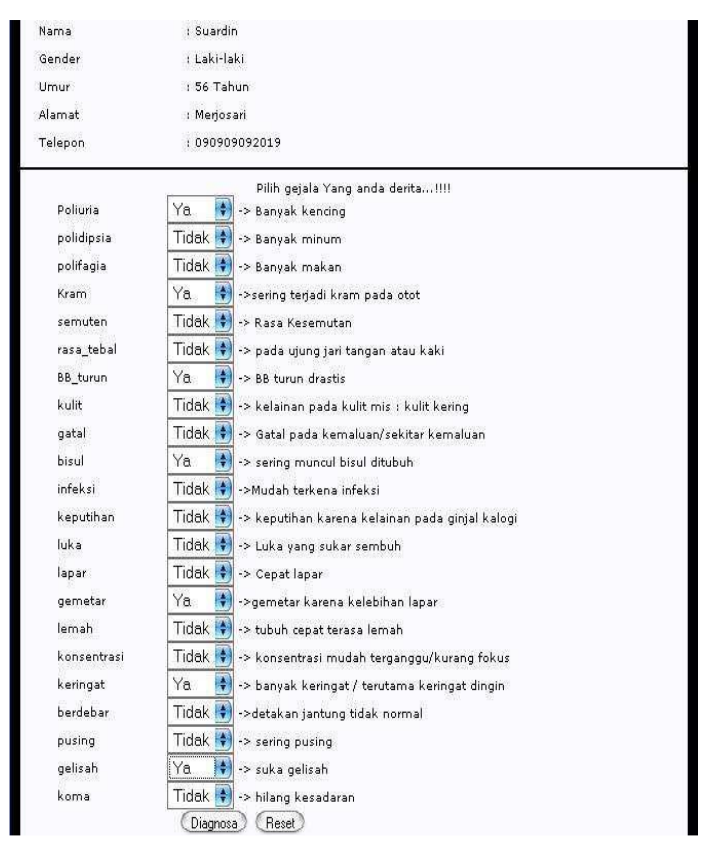

Gambar 3.1 Halaman pilih gejala

\subsection{Halaman Hasil Diagnosa}

Pada halaman ini menampilkan hasil diagnosa, berupa data pasien, gejala yang dipilih , perhitungan bayes dan juga terapi sesuai tipe diabetes yang diderita. Adapun desain halamannya sebagai berikut :

\begin{tabular}{l} 
Terdapat Gejala yang saudara masukkan : \\
* poliuria \\
* polifagia \\
* BB_turun \\
* bisul \\
* lapar \\
* berdebar \\
\hline Komputasi Penyakit YA:y \\
DIABETES (ya) $=11 / 18$ \\
Poliuria (ya) $=8 / 11$ \\
Polifagia (ya) $=9 / 11$ \\
BB Turun Drastis tanpa penyebab (ya) $=5 / 11$ \\
Sering bisulan (ya) $=2 / 11$ \\
Cepat Lapar (ya) $=2 / 11$ \\
Detakan jantung cepat (ya) $=2 / 11$ \\
\hline Hasil Ya: \\
(11/18) $*$ ( $8 / 11) *(9 / 11) *(5 / 11) *(2 / 11) *(2 / 11) *(2 / 11)$ \\
Hasil nya $=0.000993474116895$ \\
\hline Komputasi Penyakit Tidak:t \\
DIABETES (ya) $=7 / 18$ \\
Poliuria (tidak) $=3 / 7$ \\
Polifagia (tidak) $=2 / 11$ \\
BB Turun Drastis tanpa penyebab (tidak) $=6 / 11$ \\
Sering bisulan (tidak) $=9 / 11$ \\
Cepat Lapar (tidak) $=9 / 11$ \\
Detakan jantung cepat (tidak) $=9 / 11$ \\
\hline Hasil Tidak: \\
(7/18) $(3 / 7)$ \\
Hasil nya $=0.166666666667$ \\
\hline \\
Deteksi = Anda Tidak Terdeteksi Diabetes \\
\hline [klik untuk download cara suntik insulin 1 \\
\hline
\end{tabular}

Gambar 3.2 Halaman Hasil Diagnosa

\section{KESIMPULAN DAN SARAN}

1. Berdasarkan hasil pengujian dengan 10 orang, didapatkan bahwa aplikasi sistem pakar ini berguna untuk membantu dan mempermudah user dalam memperoleh informasi mengenai ganguan diabetes serta mendapatkan hasil diagnosa gangguan diabetes baik tipe 1 maupun tipe 2 .

2. Hasil perhitungan di dapatkan dari perhitungan menggunakan rumus naïve bayes dengan menghitung jumlah gejala ya dan tidak kemudian dari hasil perhitungan dijadikan perbandingan untuk mendapat kesimpulannya.

\section{DAFTAR PUSTAKA}

[1]. Adhi, Bayu.T1, Rodiyatul F. S. dan Hermansyah,2011. An Early Detection Method of Type-2 Diabetes Mellitus in Public Hospital. Telkomnika, Vol.9, No.2, August 2011, pp. 287 294.

[2]. Agustina, Tri ,2009.Gambaran Sikap Pasien Diabetes Melitus Di Poli Penyakit Dalam Rsud Dr.Moewardi Surakarta Terhadap Kunjungan Ulang Konsultasi Gizi. KTI D3. Fakultas Ilmu Kesehatan Universitas Muhammadiyah Surakarta, Surakarta.

[3]. Arhami, M. 2005. Konsep Dasar Sistem akar. Yogyakata: ANDI.

[4]. Bilous, Rudi W. 2003. Seri Kesehatan Bimbingan Dokter Pada Diabetes, Pemeriksaan Gejala, Diagnosa, Menolong Diri, Pengobatan, Gaya Hidup. Jakarta : Dian Rakyat.

[5]. Daniel T. Larose, Data Mining Methods and Models. New Jersey, USA: John Wiley and Sons, Inc, 2006

[6]. Indraswari, Wiwi.2010. Hubungan Indeks Glikemik Asupan Makanan Dengan Kadar Glukosa Darah Pada Pasien Rawat Jalan Diabetes Mellitus Tipe-2 Di Rsup Dr. Wahidin Sudirohusodo. Skripsi Sarjana. Program Studi Ilmu Gizi , Fakultas Kesehatan Masyarakat, Universitas Hasanuddin, Makassar.

[7]. Inge Martina, [2002], Pemrograman Internet dengan PHP, PT. Elex Media Komputindo, Jakarta.

[8]. Isniati, 2003, Hubungan Tingkat Pengetahuan Penderita Diabetes Militus Dengan Keterkendalian Gula Darah Di Poliklinik Rs Perjan Dr. M. Djamil Padang Tahun. Jurnal Kesehatan Masyarakat, September 2007, I (2).

[9]. Jayan. 2007. Desain Situs Keren Dengan Photoshop dan Dreamweaver. Palembang : Maxikom

[10]. Syafii, M. 2005. Membangun Aplikasi Berbasis Web PHP dan MySQL. Yogyakarta : Andi

[11]. Tandra, H. 2008. Segala Sesuatu Yang Harus Anda Ketahui Tentang Diabetes, Panduan Lengkap Mengenal dan Mengatasi Diabetes dengan Cepat dan Mudah. Jakarta : Gramedia Pustaka Utama. 